\title{
Recycled eggshells as precursors for iron-impregnated calcium oxide catalysts for partial oxidation of methane
}

\author{
Gourishankar Karoshi ${ }^{1}$, Praveen Kolar ${ }^{1 *} \mathbb{C}$, Sanjay B. Shah ${ }^{1}$ and Gary Gilleskie ${ }^{2}$
}

\begin{abstract}
There is a significant interest in converting eggshells into value-added products. Therefore, the goal of this research is to synthesize and study iron-impregnated eggshells as a catalyst for partial oxidation of methane. The objectives of this research were to test the effects of iron loading, flow rate, oxygen concentration, and temperature on methane oxidation. The catalysts were synthesized using ferric chloride hexahydrate at various loadings and tested in a heated stainless-steel reactor under different experimental conditions. The reaction products included $\mathrm{C}_{2}-\mathrm{C}_{7}$ hydrocarbons, carbon monoxide, and carbon dioxide depending on the reaction conditions. Results indicated that iron loading beyond $5 \mathrm{wt} \%$ caused a decrease in methane conversion. A decrease in oxygen concentration enhanced methane conversion with a substantial drop in the production of $\mathrm{CO}_{2}$. Besides, an increase in temperature resulted in a decrease in methane conversion with a simultaneous increase in the production of $\mathrm{CO}_{2}$ via overoxidation. The reusability experiments indicated that the catalyst was active for four reaction cycles. Our results indicate that eggshells can be used as catalyst support for methane partial oxidation and can simultaneously solve the waste disposal problems faced by the poultry industry.
\end{abstract}

Keywords: Eggshell, Iron, Methane, Catalyst, Partial oxidation

\section{Introduction}

The poultry industry worldwide produces over 8.4 billion kilograms of eggshells each year most of which is disposed as landfill wastes (Laca et al. 2017; Shahbandeh 2020). However, recent interest in newer waste management opportunities has brought eggshells to the mainstream (Mittal et al. 2016; Ahmed et al. 2019). Typically, eggshells consist of calcium carbonate $(\sim 98 \%)$, magnesium $(\sim 0.9 \%)$, phosphorus $(\sim 0.9 \%)$, and organic semipermeable membrane structures (Waheed et al. 2019; Simpson et al. 2019). Due to the presence of calcium and organic semi-permeable membranes in eggshells, several authors proposed the use of eggshells as adsorbents and catalysts. Eggshells and eggshell supported with

\footnotetext{
*Correspondence: pkolar@ncsu.edu

${ }^{1}$ Biological and Agricultural Engineering, North Carolina State University,

Campus Box 7625, Raleigh, NC 27695-7625, USA

Full list of author information is available at the end of the article
}

iron, zinc, and pyrolysis residues were evaluated as heterogeneous catalysts for transesterification of neat and waste vegetable oils (Tan et al. 2017; Borah et al. 2019; Gollakota et al. 2019; Helwani et al. 2020; Santos et al. 2019). Similarly, several researchers have tested eggshells as low-cost adsorbents for mitigation of heavy metals and other pollutants from water (Eletta et al. 2016; Mashangwa et al. 2017; Sankaran et al. 2020; Tizo et al. 2018; Zhang et al. 2017).

Besides transesterification catalysts and adsorbents, calcium-rich eggshells could also potentially be used as precursors in selective oxidation of methane. Methane constitutes about $80-90 \%$ of natural gas that is abundantly available (Horn and Schlögl 2015). Based on 2018 calculations, the world annual production of natural gas has crossed 3,900 billion cubic meters (International Energy Agency 2019). Therefore, as suggested by Sharma et al. (2020), transforming methane into fuels and chemicals is of high priority. 
However, cracking methane and converting into chemicals are difficult because of the inertness of methane and higher bond disassociation energies than the reaction products (Schwach et al. 2017; York et al. 2003). Hence, researchers are exploring active and selective catalysts for partial oxidation of methane (Hutchings 2016).

In nature, methane is selectively oxidized via methane monooxygenase by the catalytic activity of iron (soluble form) and copper (particulate form) species (Ravi et al. 2017). Therefore, several researchers have investigated iron (and copper) based catalysts for selective oxidation of methane. Cherrak et al. (1992) reported enhanced $C_{2}$ selectivity upon the introduction of $\mathrm{Fe}$ on bismuth vanadate-based catalyst. Michalkiewicz (2004) investigated partial oxidation of methane using an iron-impregnated zeolite catalyst and reported methanol and formaldehyde as the products. Attempts have also been made to disperse the $\mathrm{FeOx}$ clusters and $\mathrm{Cu}^{2+}$ ions on silica to improve catalytic oxidation of methane into formaldehyde (Wang et al. 2010). In their research, Vereshchagin et al. (2012) reported highly active ferrosphere catalysts composed of 36-93 wt\% $\mathrm{Fe}_{2} \mathrm{O}_{3}$ for oxidative coupling of methane with emphasis on catalyst preparation approach as well as the phase changes of the catalyst components. $\mathrm{Xu}$ et al. (2016) reported selective oxidation of methane into methanol over copper and iron co-impregnated on the Zeolite Socony Mobil 5 (ZSM-5) catalyst using hydrogen peroxide as an oxidant. Recently, an ironimpregnated mordenite catalyst was evaluated for the conversion of methane into formic acid, methanol, and formaldehyde (Fang et al. 2019). Therefore, based on the reports in the literature, it appears that iron can catalyze selective oxidation of methane.

Our research group is also interested in the value-addition of poultry industry wastes. In that context, we had previously reported that calcined eggshells and copperimpregnated eggshells can catalyze selective oxidation of methane (Karoshi et al. 2015, 2020). Considering that there are no reports in the literature on the efficacy of the eggshell-supported iron catalysts for selective oxidation of methane, the present research evaluated eggshellimpregnated iron as a catalyst for oxidation of methane. From a waste management perspective, using eggshells as support material will not only decrease the waste disposal problems but also add value to an otherwise waste stream. Based on our previous research, it is hypothesized that the calcium present in the eggshell coupled with iron can catalyze selective oxidation of methane. The objectives were to investigate the effects of (1) loading of iron, (2) the molar ratio of methane to oxygen (3) flow rate, and (4) temperature on the methane conversion and products.

\section{Materials and methods Catalyst preparation}

The catalyst was synthesized by impregnating three different concentrations ( 2,5 , and $10 \%$ by weight) of iron on eggshell supports. Briefly, ferric chloride hexahydrate $\left(\mathrm{FeCl}_{3} \cdot 6 \mathrm{H}_{2} \mathrm{O}\right)$ was used to deposit the metal using a wet impregnation method. Eggshell particles $(2-5 \mathrm{~mm}$ in size) were mixed with aqueous ferric chloride solutions prepared in proportionate volume $\left(1 \mathrm{~mL} \mathrm{~g}^{-1}\right.$ of eggshells used) of deionized water for $5 \mathrm{~h}$ at $300 \mathrm{rpm}$ at room temperature. Subsequently, the iron-impregnated catalysts were dried at $105^{\circ} \mathrm{C}$ for $8 \mathrm{~h}$ and then calcined at $1000^{\circ} \mathrm{C}$ for $4 \mathrm{~h}$.

\section{Catalyst characterization}

The surfaces (fresh and spent as applicable) of iron-impregnated eggshell catalysts were analyzed at the NC State University Advanced Instrumentation Facility using two analytical techniques: time-of-flight secondary ion mass spectrometer (TOF-SIMS) and variable pressure scanning electron microscopy (VPSEM). Briefly, the samples were placed in a TOF SIMS (ION TOF, Inc. Chestnut Ridge, $\mathrm{NY}) @ 5.0 \times 10^{-9}$ mbar and analyzed via a $\mathrm{Bi}_{\mathrm{n}}{ }^{\mathrm{m}+}(\mathrm{n}=1-5$, $\mathrm{m}=1,2$ ) liquid metal ion gun and a $\mathrm{Cs}^{+}$sputtering gun. Similarly, for studying the surface morphological data, the samples were sputter coated $(\sim 35 \mathrm{~nm})$ with gold $(60 \%)$ and palladium (40\%) to enhance the conductivity of the catalyst surface. Subsequently, the sample surfaces were analyzed in a $10^{-6}$ Torr VPSEM (Hitachi S 3200) using a $20 \mathrm{keV}$ electron beam.

\section{Catalyst testing}

All experiments were performed in a stainless-steel tubular reactor $(2.5 \mathrm{~cm}$ diameter and $15 \mathrm{~cm}$ height) that was enclosed in a kiln. A 10-g catalyst sample was loaded into the reactor in which methane ( $99 \%$ purity) and oxygen (99.9\% purity) were fed to the reactor. Before the commencement of each experiment, the catalyst was activated at $650{ }^{\circ} \mathrm{C}$ for $60 \mathrm{~min}$. Subsequently, separate experiments were conducted to study the effects of iron loading (2, 5 , and $10 \%)$ and molar ratios of methane to oxygen (1.0, 1.67 , and 3.0) on methane oxidation and product selectivity. Similarly, to determine the effect of flow rate $(0.4,0.8$, and $1.2 \mathrm{~L} \mathrm{~min}^{-1}$ ) and temperature $\left(650,700\right.$, and $750{ }^{\circ} \mathrm{C}$ ), a molar ratio of 3 and $10 \mathrm{~g}$ catalyst with a $2 \%$ metal loading was employed. Furthermore, additional experiments were also performed to determine the catalyst durability by reusing the catalyst for four oxidation cycles. For all experiments, after attaining equilibrium, inlet and outlet gas samples and flow rates were collected at 10- and 15-min intervals and analyzed for concentrations of the reactants and products to determine the fractional conversion and 
selectivity (Karoshi et al. 2015). Gas analyses were conducted via a gas chromatograph equipped with a mass spectrometer (HP 5 MS column) and a thermal conductivity detector (Carbosieve SII column).

\section{Results and discussion \\ Catalyst characterization}

The formation of $\mathrm{CaO}$ active phase was confirmed via SIMS-TOF data via the occurrence of $\mathrm{CaOH}+$ and $\mathrm{CaO}+$ functional groups, as shown in Fig. 1a. Chloride distribution was observed to be present all over the catalyst surface and suggests an arrangement of chloride ions along the pore channels in eggshells. Furthermore, upon hightemperature activation, chloride was observed to migrate from $\mathrm{FeCl}_{3}$ to interact with calcium present in eggshell. Visual observation showed that increasing $\mathrm{FeCl}_{3}$ loading led to clumping of catalyst particles, possibly minimizing accessible active sites for the reaction. During catalyst preparation, aqueous $\mathrm{FeCl}_{3}$ may have reacted with $\mathrm{CaCO}_{3}$ in the eggshell to exchange chlorine as well as to change the $\mathrm{pH}$ substantially because of the release of $\mathrm{HCl}$ and $\mathrm{CO}_{2}$ (Eqs. 1 and 2):

$$
\begin{aligned}
& \mathrm{FeCl}_{3}+3 \mathrm{H}_{2} \mathrm{O} \rightleftharpoons \mathrm{Fe}(\mathrm{OH})_{3}+3 \mathrm{HCl} \\
& \mathrm{CaCO}_{3}+2 \mathrm{HCl} \rightleftharpoons \mathrm{CaCl}_{2}+\mathrm{CO}_{2}+\mathrm{H}_{2} \mathrm{O} .
\end{aligned}
$$

The mass spectral images suggested that iron was arranged both as clusters and in a well-distributed planar way (Fig. 1b). Hence, calcium overlapping with iron was observed in both situations, as depicted in Fig. 1a and c.

Interestingly, the energy-dispersive spectroscopy (EDS) data collected via VPSEM analysis for $2 \%$ Fe-loaded eggshell catalysts indicated that the metal loading both in the form of a cluster as well as in a widely distributed manner on the surface (Fig. 2a) suggesting a heterogeneous surface. Unique surface morphology resembling a surface with settled molten metal was observed, perhaps due to the low melting point of $\mathrm{FeCl}_{3}\left(\sim 300^{\circ} \mathrm{C}\right)$ which may have spread over the eggshell support. Furthermore, partial dissolution of iron clusters into the eggshell catalyst support is possible (El-Shobaky and Fahmy 2006). Besides, the analysis of the spent catalyst exhibited significantly deformed surface morphology (Fig. 2b, c) with enhanced porosity suggesting possible momentum effects of the feed gas.

\section{Effect of metal loading}

The experimental data suggested that at $2 \%$ loading, iron impregnation did not have any effect on the fractional conversion of methane when compared to plain calcined eggshell (control). However, with an increase in metal concentration, a substantial drop in methane conversion was observed, as shown in Fig. 3a. This may be attributed to the migration of chloride to $\mathrm{Ca}$ inherent to eggshell forming an inactive $\mathrm{CaCl}_{2}$ phase during catalyst preparation (Eqs. 1 and 2). Furthermore, the relatively lower melting point of $\mathrm{FeCl}_{3}$ would have enhanced the distribution of its molten phase, masking active $\mathrm{CaO}$ sites on the eggshell.

Furthermore, $\mathrm{C}_{2}-\mathrm{C}_{7}$ hydrocarbons (ethane, ethylene, propene, 1,3-butadiene, pentene, pentadiene, benzene, and toluene) along with $\mathrm{H}_{2}$ and $\mathrm{CO}_{x}$ were identified as part of the product spectrum. As suggested by Ibrahim et al. (2015), the interaction between the catalyst and the support material may have played a role in the selectivity of the catalyst. In addition, as observed by Lim et al. (2019), the basicity of the eggshell support may have also influenced the catalytic activity and selectivity. The results indicated that the production of $\mathrm{CO}_{2}$ did not vary considerably with iron concentration. However, $10 \%$ loading, despite possessing higher metal concentration, led to a drop in $\mathrm{CO}_{2}$ production. A drop in $\mathrm{CO}_{2}$ production was not compensated with enhanced selectivity for other products, and rather, the production of $\mathrm{C}_{2}-$ $\mathrm{C}_{6}$ hydrocarbons dropped simultaneously, as shown in Fig. 3b, c. This phenomenon suggests the possible existence of an alternative pathway leading to products that were not detected by our analytical system. Based on our results, a $2 \%$ Fe-loaded catalyst was chosen for further analysis, since iron loading beyond $2 \%$ substantially reduced methane activation.

\section{Effect of $\mathrm{CH}_{4}: \mathrm{O}_{2}$}

When the effects of molar ratios were studied, the fractional conversion of methane increased with decreasing oxygen proportion in the feed, as shown in Fig. 4a. This may be explained by the fact that oxygen and methane in the feed compete to adsorb on the catalytic surface. Reducing oxygen concentration will pose minimal constraint for methane molecules to adsorb on the catalyst surface. This would have led to the enhanced conversion of methane. Furthermore, it is theorized that at a lower concentration of oxygen, $\mathrm{Fe}_{2} \mathrm{O}_{3} / \mathrm{Fe}-\mathrm{O}$ clusters may also have contributed towards methane activation.

The selectivity for $\mathrm{CO}_{2}$ dropped rapidly with a reduction in oxygen concentration in the feed, suggesting dominant selective oxidation reaction (Fig. 4b). Similar behavior was observed with eggshell-supported catalysts (Karoshi et al. 2020). However, the decrease in $\mathrm{CO}_{2}$ selectivity was also accompanied by the drop in $\mathrm{C}_{2}-\mathrm{C}_{6}$ hydrocarbon selectivities (Fig. $4 \mathrm{c}$ ), corroborating the observation of alternative pathways and products that were undetected by the gas chromatograph system employed in our research that was also evident from the 
a

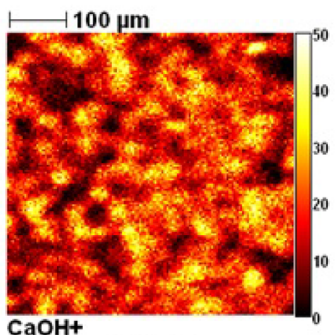

$\mathrm{mc}: 50 \mathrm{tc}: 2.86 \mathrm{e}+5$

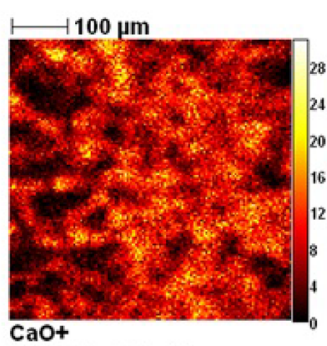

$\mathrm{mc}: 31$ tc: $1.28 \mathrm{e}+5$
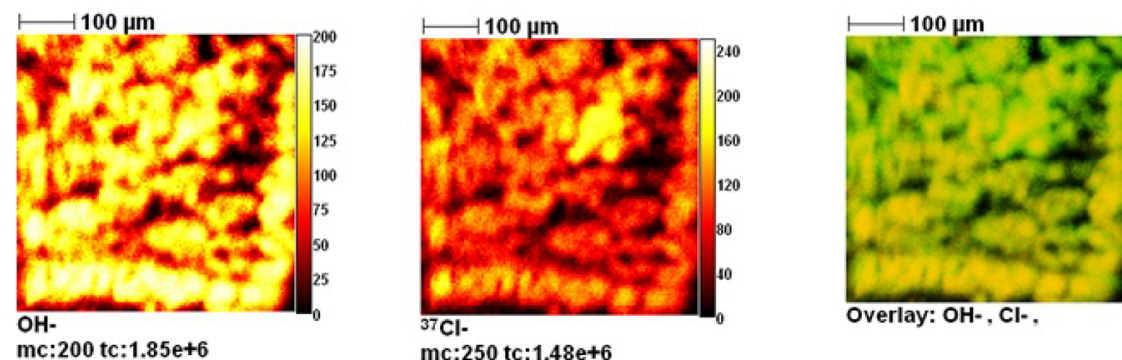

$\mathrm{mc}: 250 \mathrm{tc}: 1.48 \mathrm{e}+6$
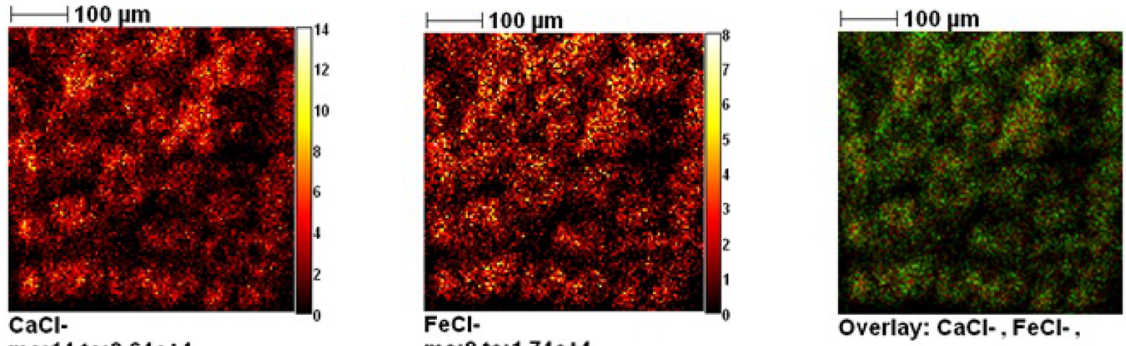

$\mathrm{mc}: 14$ tc:2.64e+4

$\mathrm{mc}: 8$ tc: $1.74 \mathrm{e}+4$

Overlay: $\mathrm{CaCl}, \mathrm{FeCl}-$,

b

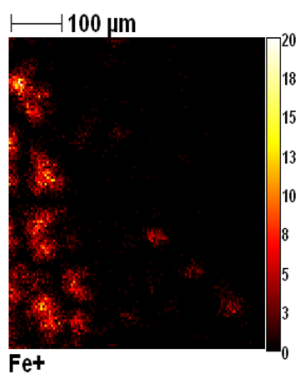

$\mathrm{mc}: 20 \mathrm{tc}: 7.01 \mathrm{e}+3$

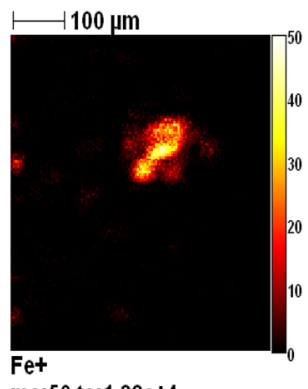

$\mathrm{mc}: 50 \mathrm{tc}: 1.28 \mathrm{e}+4$

C
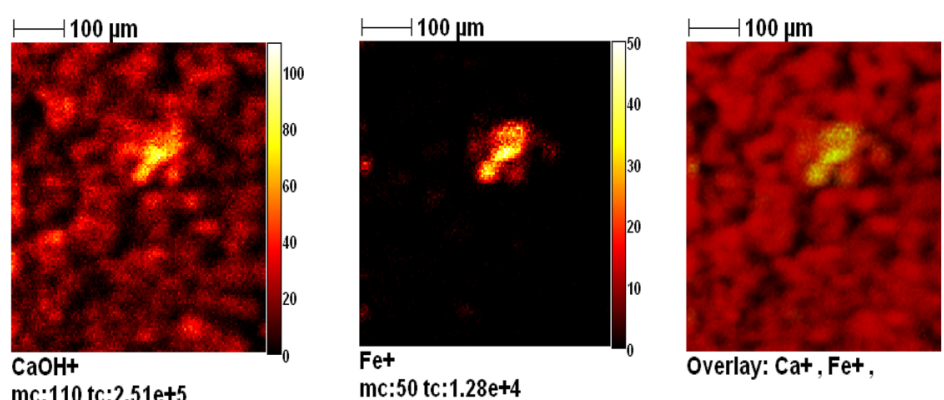

$\mathrm{mc}: 50 \mathrm{tc}: 1.28 \mathrm{e}+4$

Overlay: $\mathrm{Ca}+, \mathrm{Fe}+$,

Fig. 1 SIMS-TOF mass spectral images for 2\% Fe-loaded eggshell catalyst representing (a) distribution of Ca and Fe in different forms, (b) distribution of Fe clusters, and (c) relative distribution of Fe \& Ca 


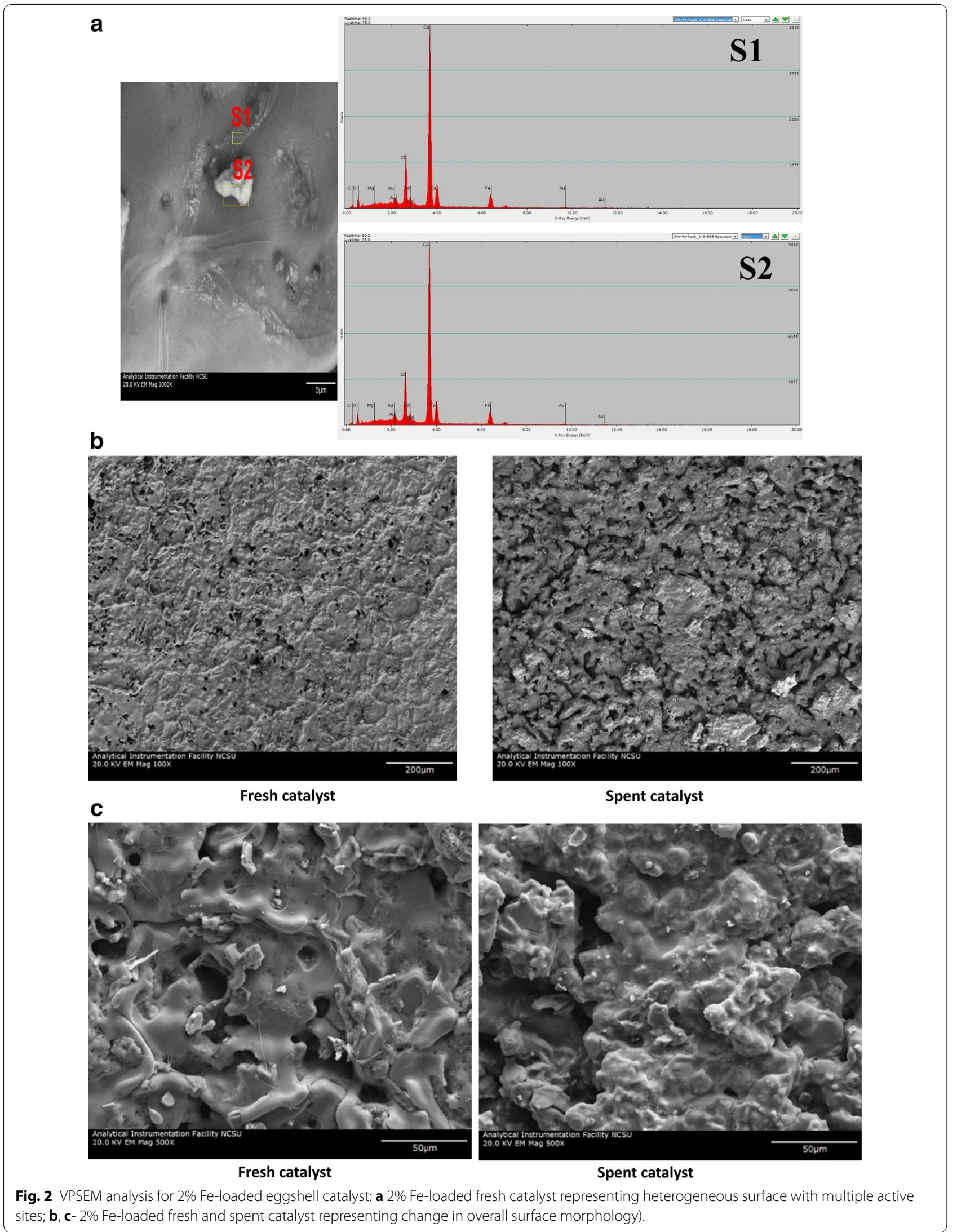



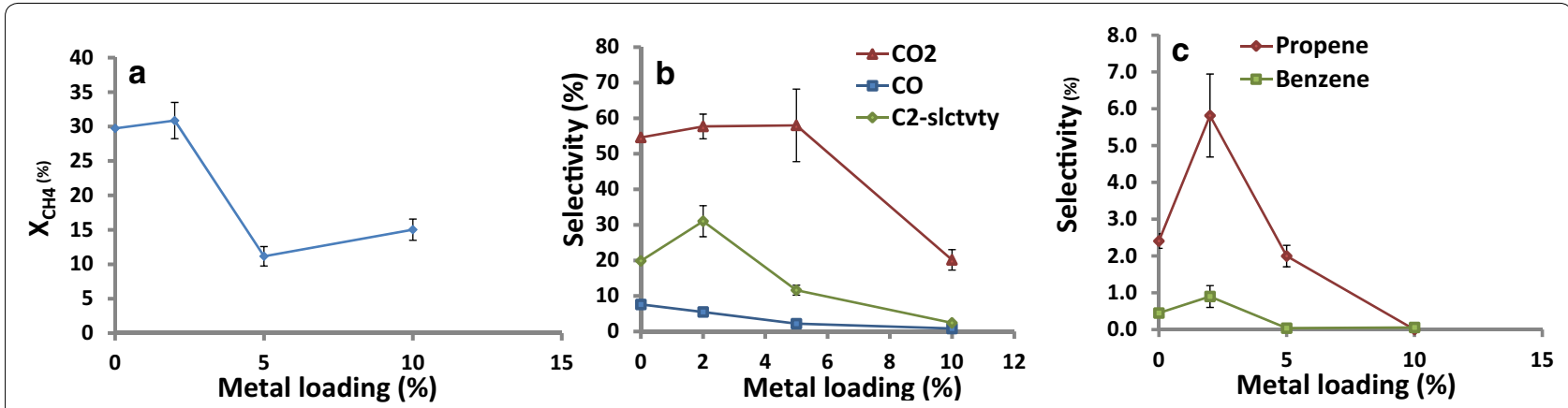

Fig. 3 Effect of iron loading (wt\%) on (a) conversion of methane, (b) yield of $\mathrm{C}_{2}$ hydrocarbons and carbon oxides, (c) yield of $\mathrm{C}_{3}-\mathrm{C}_{6}$ hydrocarbons under the experimental conditions: $650^{\circ} \mathrm{C}, 0.8 \mathrm{~L} / \mathrm{min}, 10 \mathrm{~g}$ catalyst and $\mathrm{CH}_{4}: \mathrm{O}_{2}=1: 1.0 \%$ control (calcined eggshell without metal loading)

carbon balance. Furthermore, these observations were also supported by the data collected from temperature experiments as will be discussed later in the article. With reduced oxygen concentration in the feed, the drop in production of ethylene was greater than the reduction in ethane production, as shown in Fig. 4d. Besides, measured high oxygen conversions of 95-97\% suggest the possibility of the presence of oxygenates as part of unknown products.

\section{Effect of flowrate}

An initial increase in flow rate enhanced the fractional conversion of methane probably because of adequate mixing that facilitates easy access of catalytic sites for reactants. However, with a further increase in flowrate, a rapid drop in methane conversion was observed suggesting inadequate residence time for methane activation (Fig. 5a). Thus, both mass transfer and residence time constraints are critical in obtaining the desired methane conversion rate. The deposition of $\mathrm{FeCl}_{3}$ on eggshell

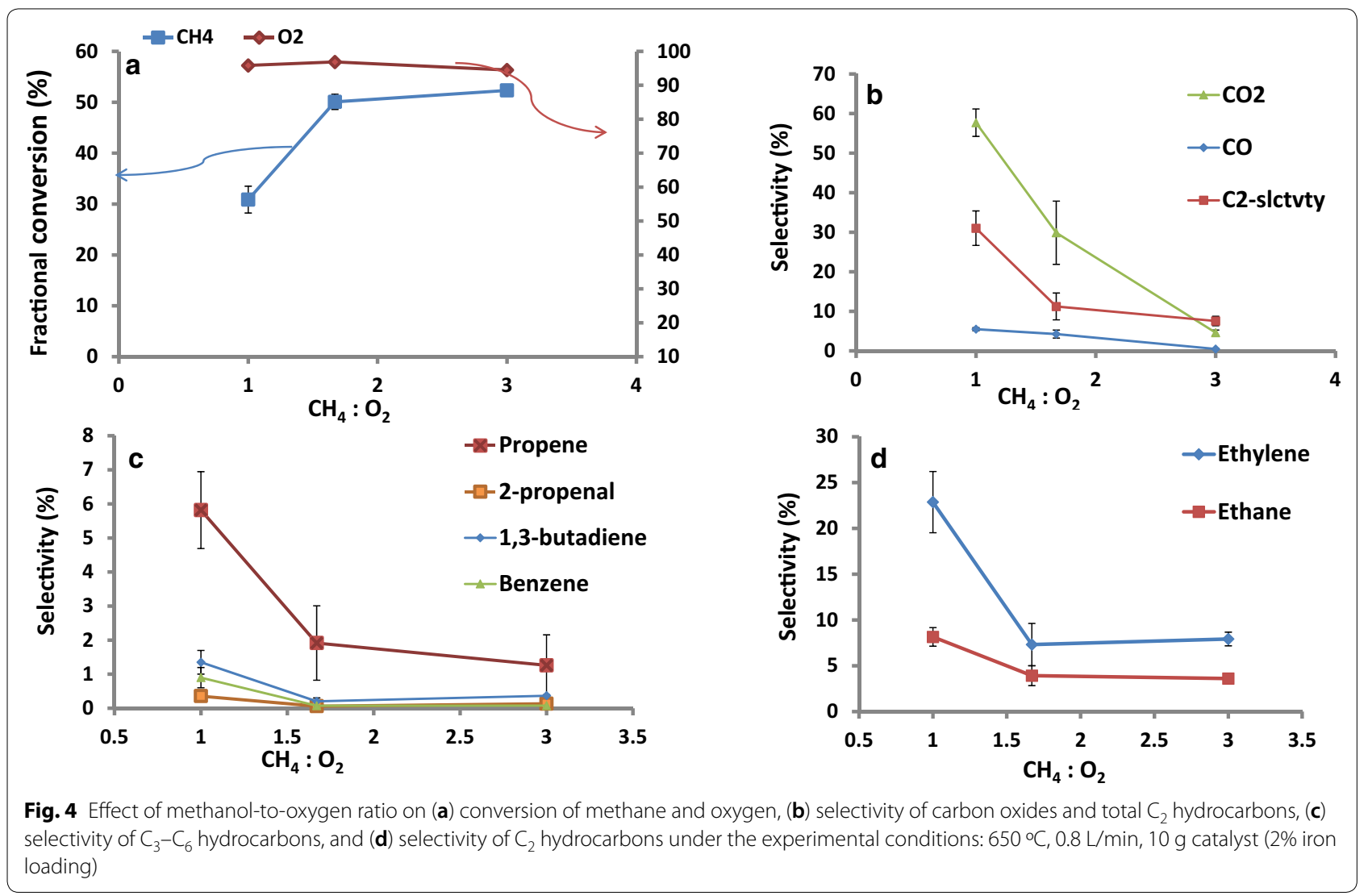


support may mask $\mathrm{CaO}$ clusters to a certain extent as is evident from the earlier observations with different metal concentrations. Lower flowrate with high residence time may not supply adequate energy for reactant methane molecules to diffuse in the catalyst bed to access many $\mathrm{CaO}$ active sites and hence releasing most of them unreacted from the reactor. Additionally, $\mathrm{FeCl}_{3}$ could have been relatively more mobile because of the lower melting point $(\sim 308 \mathrm{C})$ when the feed gas was flown at higher flow rates. This could restrict the access of reactant methane molecules to $\mathrm{CaO}$ clusters which are believed to be the cause for methane activation. Such mobility and molten state settlement of $\mathrm{FeCl}_{3}$ were confirmed via VPSEM magnified images, as shown in Fig. 2.

Production of $\mathrm{CO}_{2}$ and $\mathrm{C}_{2}$ hydrocarbons decreased with an initial increase in flowrate and was enhanced with a further increment of flowrate but at a lower methane conversion (Fig. 5b). Interestingly, no quantifiable concentration $>\mathrm{C}_{3}$ hydrocarbons was observed at a higher flow rate of $1.2 \mathrm{~L} / \mathrm{min}$ (Fig. 5c). This suggested that inadequate residence time would not have permitted multiple adsorption and desorption steps for reactants to form higher hydrocarbons. On the other hand, with a lower flow rate, the tendency of target products to overoxidize into carbon dioxide will prevail causing lower selectivity. In one of their reports, Roseno et al (2016) investigated catalytic partial oxidation of methane via perovskite-type catalysts ( $\mathrm{La}-\mathrm{Co} / \mathrm{Fe}-\mathrm{O}$ ) under different experimental conditions. The authors observed a strong dependence of fractional conversion and product $\left(\mathrm{CO}, \mathrm{CO}_{2}\right.$, and $\left.\mathrm{C}_{2}\right)$ selectivity on residence time, indicating that optimal residence time is necessary for balancing fractional conversion and overoxidation. Similarly, Grunwaldt et al (2001) studied partial oxidation of methane on rhodium-impregnated on alumina catalysts and reported that the residence time influenced the product selectivity. Hence, balance between adequate residence time and sufficient turbulence is essential to enhance yields of target products. This conclusion was further evident from the data of variation in ethylene and ethane proportions in the product stream (Fig. 5d). With increasing flowrate, selectivity for ethane was greater than that for ethylene, indicating a lack of secondary selective oxidation step due to lower residence time. It was observed that carbon balance improved whenever $\mathrm{CO}_{2}$ production dominated product distribution.

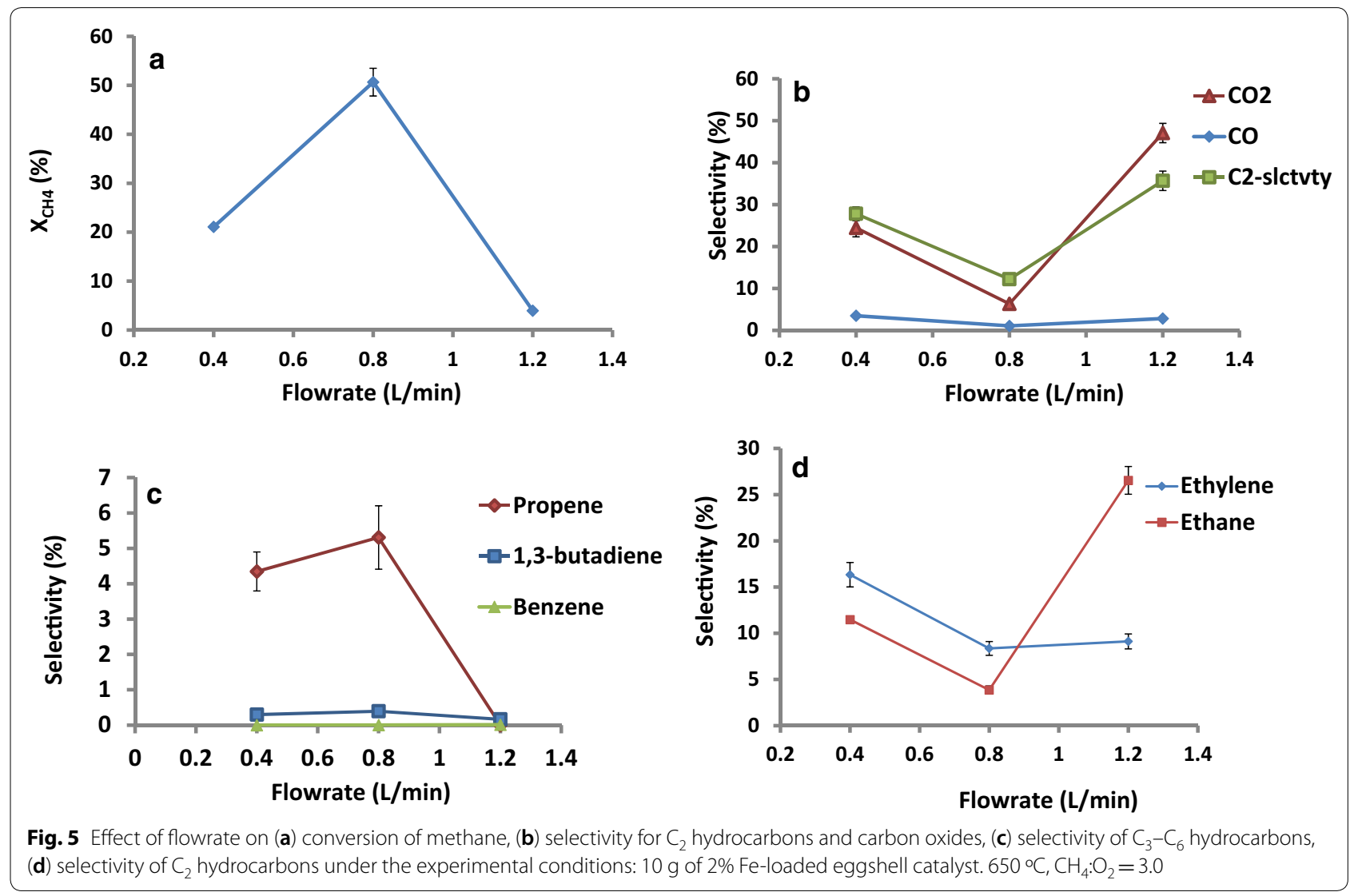




\section{Effect of temperature}

The results suggested that the fractional conversion of methane for iron-impregnated eggshell catalysts decreased with increasing temperature (Fig. 6a). The methane conversion decreased by about $55 \%$ when the reaction temperature increased from 650 to $750{ }^{\circ} \mathrm{C}$. Our results are in contrast to those reported by (Lim et al. 2019), who investigated perovskite-supported alkaline earth metal oxides for oxidative coupling of methane. The authors reported an increase in methane fractional conversion when temperatures were increased from 600 to $725^{\circ} \mathrm{C}$ for all calcium, strontium, and barium-based catalysts. Besides, Michalkiewicz (2004) investigated partial oxidation of methane on zeolite-supported iron catalysts. It was observed that the fractional conversion of methane increased with an increase in reaction temperature from 350 to $650{ }^{\circ} \mathrm{C}$, while the selectivity of methanol decreased due to overoxidation of methanol into formaldehyde and $\mathrm{CO}_{2}$. The substantial drop in fractional conversion at higher temperatures may be due to catalyst deactivation via sintering. Barbosa et al. (2001) studied iron-based catalysts for combustion of methane and reported the occurrence of sintering effects of the catalysts tested. In addition, as suggested by Ibrahim et al. (2015), the interaction between the catalyst support and the catalyst may have played an important role in the overall activity of the catalyst. In our research, the drop in methane conversion can also be attributed to both possible $\mathrm{Ca}-\mathrm{Fe}$ interaction as well as to relatively higher mobility of $\mathrm{FeCl}_{3}$ because of its low melting point. With increasing temperature coupled with the physical impact of feed gas flow, the mobility of $\mathrm{FeCl}_{3}$ is believed to be enhanced significantly. Such mobility would cause $\mathrm{FeCl}_{3}$ to mask the $\mathrm{CaO}$ active sites inherent to eggshell support. Therefore, to understand the surface chemistry of the catalyst, additional systematic studies on the catalyst characterization via XRD, XPS, and TPD are suggested. Besides, increased $\mathrm{CO}_{2}$ production with a simultaneous drop in $\mathrm{C}_{2}-\mathrm{C}_{6}$ hydrocarbons was observed because of the overoxidation (Fig. 6b, c). While a slight increase in ethane concentration was observed, ethylene production remained nearly the same at all the temperatures tested (Fig. 6d).

Moreover, an overall carbon balance was also performed for the experiments at different temperatures. The overall amount of unaccounted carbon reduced with an increase in temperature, as shown in Fig. 6e. With a simultaneous increase in $\mathrm{CO}_{2}$ selectivity under the same conditions, overoxidation of reaction products seems possible. This further supports the idea of possible existence of reaction products that were not identified by the gas chromatograph.
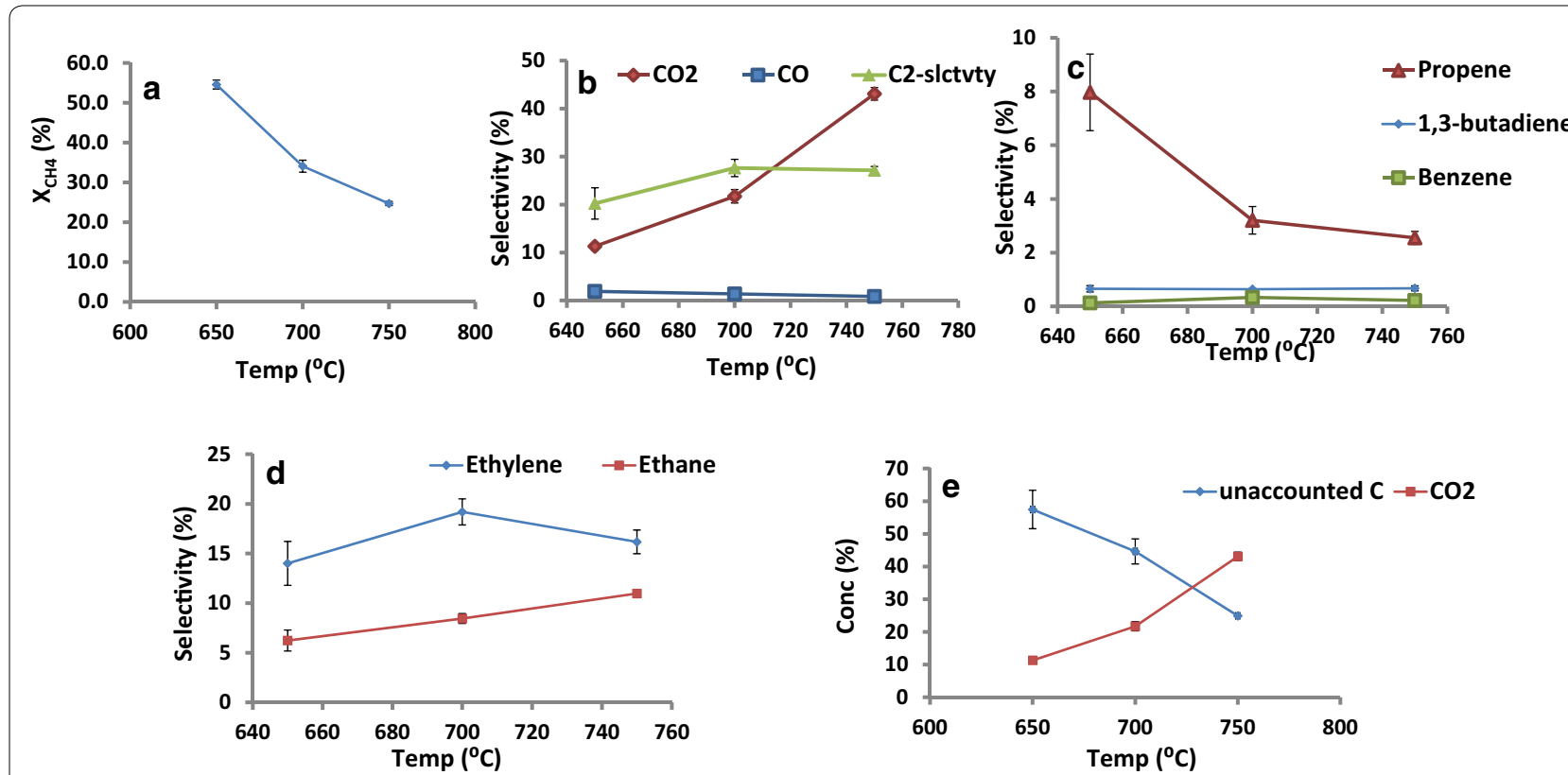

Fig. 6 Effect of temperature on (a) conversion of methane, (b) selectivity for $C_{2}$ hydrocarbons and carbon oxides, (c) selectivity for $C_{3}-C_{6}$ hydrocarbons, (d) $\mathrm{C}_{2}$ hydrocarbons, and (e) carbon balance and $\mathrm{CO}_{2}$ production under the experimental conditions: $10 \mathrm{~g}$ of $2 \%$ Fe-loaded eggshell catalyst. $800 \mathrm{~mL} / \mathrm{min}, \mathrm{CH}_{4}: \mathrm{O}_{2}=3$ 


\section{Longevity}

As depicted in Fig. 7a, the catalyst was found to achieve consistent methane conversion over multiple cycles. However, a considerable increase in the production of $\mathrm{CO}_{2}$ was observed after the first cycle of operation (Fig. 7b). Analyzing these results in the light of VPSEM images depicting high porosity in the spent catalyst and high mobility of $\mathrm{FeCl}_{3}$ it appeared that high porosity along with mobile $\mathrm{FeCl}_{3}$ would have provided an enhanced number of $\mathrm{Fe}_{2} \mathrm{O}_{3} / \mathrm{FeO}$ clusters, resulting in enhanced oxidation and $\mathrm{CO}_{2}$ production. Furthermore, secondary collisions of products within the catalyst may have caused complete oxidation to $\mathrm{CO}_{2}$ (Cullis 1967). Furthermore, as described by (Enger et al. 2008), the creation of hotspots and temperature gradient zones during oxidation of methane would also contribute to enhanced $\mathrm{CO}_{2}$ selectivity that was also enhanced via the heat entrapment due to the possible molten state of the catalyst surface. On the other hand, the selectivity for other target products remained nearly similar over time. Unaccounted carbon was observed to reduce with each cycle as the products were inclined to overoxidize because of secondary collisions and heat entrapment (Fig. 7c, d).

\section{Conclusion}

Waste eggshells were employed as a precursor for the synthesis of an iron-impregnated calcium oxide catalyst for partial oxidation of methane. Experimental results suggested that the oxygen concentration in the feed appeared to have a dominant effect on methane activation and selectivity for target products of interest. Iron loading beyond $2 \mathrm{wt} \%$ did not yield substantial methane conversion and product yields, while higher temperatures seem to decrease the fractional conversion of methane. The catalyst was observed to provide consistent methane conversion over multiple cycles, but the enhanced porosity and heat entrapment enhanced overoxidation of target products into $\mathrm{CO}_{2}$. Additional studies focused on catalyst characterization to understand and relate the surface chemistry of the catalyst to its activity are suggested.
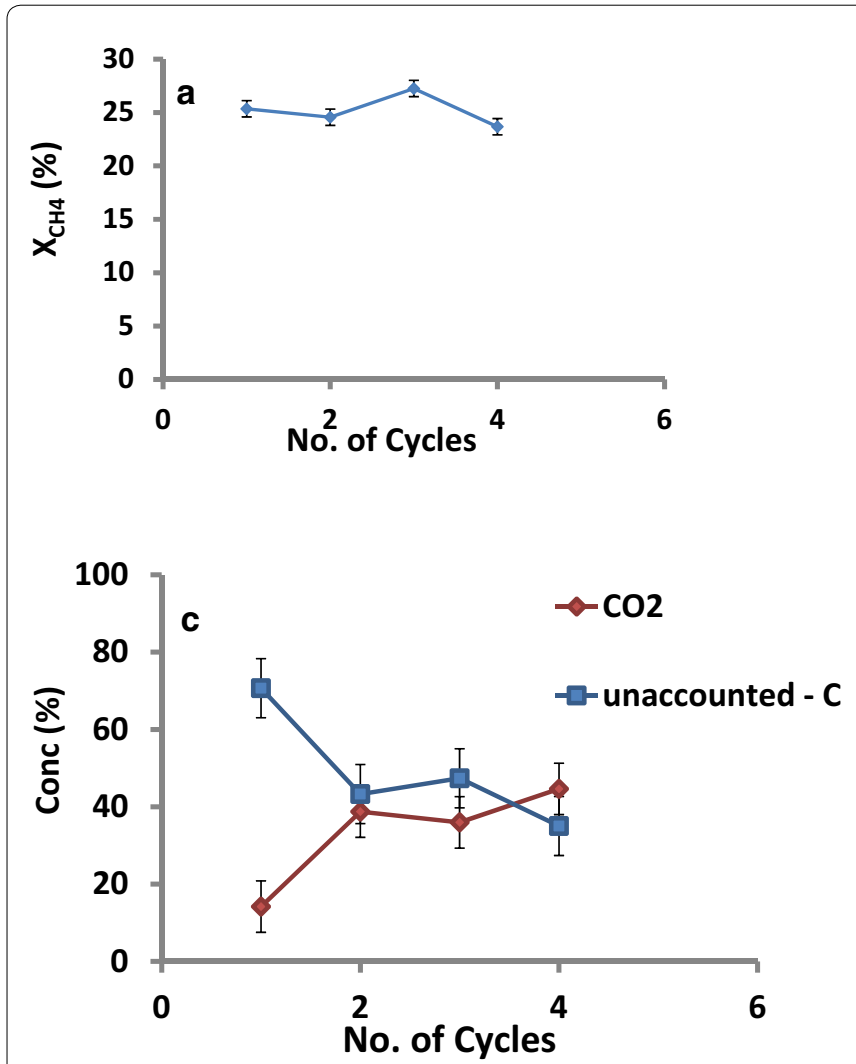

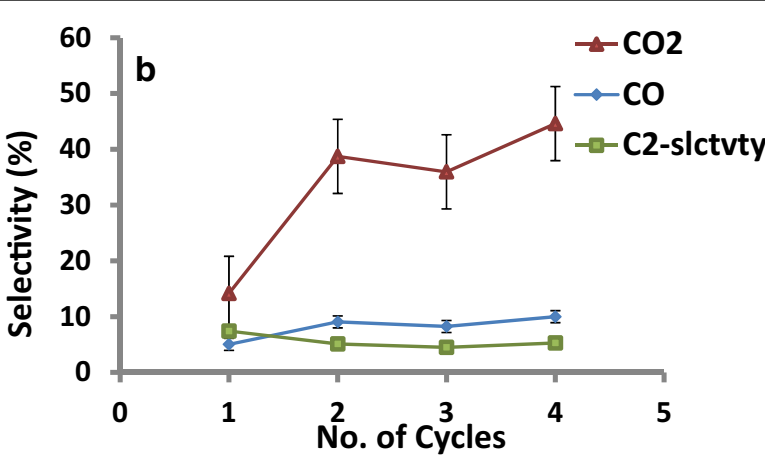

d

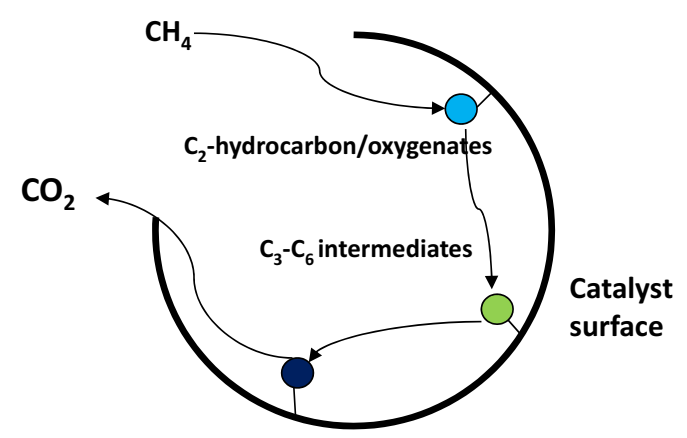

Fig. 7 Effect on catalyst recyclability on (a) conversion of methane with multiple cycles involving reactivation of catalysts via flow of pure oxygen, (b) selectivity for end products, and (c) carbon balance under the experimental conditions $650^{\circ} \mathrm{C}, 0.8 \mathrm{~L} / \mathrm{min}, 10 \mathrm{~g}$ catalyst, and $\mathrm{CH}_{4}: \mathrm{O}_{2}=3: 1$. Periodic reactivation via $\mathrm{O}_{2}$ at $0.8 \mathrm{~L} / \mathrm{min}$ and $\mathrm{He}-1 \mathrm{~L} / \mathrm{min}$; (d) schematic representation of secondary collision of intermediate products undergoing complete oxidation into $\mathrm{CO}_{2}$ 


\section{Abbreviations}

TOF-SIMS: Time-of-flight secondary ion mass spectrometer; VPSEM: Variable pressure scanning electron microscopy.; ZSM-5: Zeolite Socony Mobil 5; EDS: Energy-dispersive spectroscopy.

\section{Acknowledgements}

The authors would like to thank Mr. Chuck Mooney and Dr. Elaine Zhou for help with catalyst characterization.

\section{Authors' contributions}

GK performed the experiments and wrote the first draft of the manuscript under the constant technical guidance of PK, SBS, and GG. PK revised the manuscript and PK, SBS, and GS provided the research idea along with analytical help to GS, and reviewed the text. All authors read and approved the final manuscript.

\section{Funding}

This work was supported by hatch funds from the USDA National Institute of Food and Agriculture.

\section{Availability of data and materials}

The datasets used and/or analyzed during the current study are available from the corresponding author on reasonable request.

\section{Ethics approval and consent to participate}

Not applicable.

\section{Consent to publication}

Not applicable.

\section{Competing interests}

The authors declare that they have no competing interests.

\section{Author details}

1 Biological and Agricultural Engineering, North Carolina State University, Campus Box 7625, Raleigh, NC 27695-7625, USA. ${ }^{2}$ Golden LEAF Biomanufacturing Training \& Education Center, North Carolina State University, Campus Box 7928, Raleigh, NC 27695-7928, USA.

Received: 19 March 2020 Accepted: 7 August 2020

Published online: 17 August 2020

\section{References}

Ahmed TA, Kulshreshtha G, Hincke MT (2019) Value-added uses of eggshell and eggshell membranes. In: Jianping Wu (ed) Anonymous eggs as functional foods and nutraceuticals for human health. Royal Society of Chemistry, Cambridge, pp 359-397

Barbosa AL, Herguido J, Santamaria J (2001) Methane combustion over unsupported iron oxide catalysts. Catal Today 64:43-50

Borah MJ, Das A, Das V et al (2019) Transesterification of waste cooking oil for biodiesel production catalyzed by Zn substituted waste egg shell derived CaO nanocatalyst. Fuel 242:345-354

Cherrak A, Hubaut R, Barbaux Y, Mairesse G (1992) Catalytic properties of bismuth vanadates based catalysts in oxidative coupling of methane and oxidative dehydrogenation of propane. Catal Lett 15:377-383

Cullis CF (1967) Heterogeneous catalytic oxidation of hydrocarbons. Ind Eng Chem 59(12):19-27

Eletta O, Ajayi OA, Ogunleye OO et al (2016) Adsorption of cyanide from aqueous solution using calcinated eggshells: equilibrium and optimisation studies. J Environ Chem Eng 4(1):1367-1375

El-Shobaky HG, Fahmy YM (2006) Cordierite as catalyst support for nanocrystalline CuO/Fe2O3 system. Mater Res Bull 41(9):1701-1713

Enger BC, Lødeng R, Holmen A (2008) A review of catalytic partial oxidation of methane to synthesis gas with emphasis on reaction mechanisms over transition metal catalysts. Appl Catal A 346(1-2):1-27

Fang Z, Murayama H, Zhao Q et al (2019) Selective mild oxidation of methane to methanol or formic acid on Fe-MOR catalysts. Catal Sci Technol 9(24):6946-6956
Gollakota A, Volli V, Shu C (2019) Transesterification of waste cooking oil using pyrolysis residue supported eggshell catalyst. Sci Total Environ 661:316-325

Grunwaldt J-D, Basini L, Clausen BS (2001) In situ EXAFS study of Rh/Al2O3 catalysts for catalytic partial oxidation of methane. J Catal 200:321-329

Helwani Z, Ramli M, Saputra E et al (2020) Impregnation of CaO from eggshell waste with magnetite as a solid catalyst (Fe3O4/CaO) for transesterification of palm oil off-grade. Catalysts 10(2):164

Horn R, Schlögl R (2015) Methane activation by heterogeneous catalysis. Catal Lett 145(1):23-39

Hutchings GJ (2016) Methane activation by selective oxidation. Top Catal 59(8-9):658-662

Ibrahim AA, Fakeeha AH, Al-Fatesh AS et al (2015) Methane decomposition over iron catalyst for hydrogen production. Int J Hydrogen Energy 40(24):7593-7600

International Energy Agency (2019) IEA Atlas of energy. International Energy Agency, Paris

Karoshi G, Kolar P, Shah SB et al (2015) Calcined eggshell as an inexpensive catalyst for partial oxidation of methane. J Taiwan Inst Chem Eng 57:123-128

Karoshi G, Kolar P, Shah SB et al (2020) Valorization of eggshell waste into supported copper catalysts for partial oxidation of methane. Int J Environ Res 14(1):61-70

Laca A, Laca A, Díaz M (2017) Eggshell waste as catalyst: a review. J Environ Manage 197:351-359

Lim S, Choi J, Suh DJ et al (2019) Low-temperature oxidative coupling of methane using alkaline earth metal oxide-supported perovskites. Catal Today 352:127-133

Mashangwa TD, Tekere M, Sibanda T (2017) Determination of the efficacy of eggshell as a low-cost adsorbent for the treatment of metal laden effluents. Int J Environ Res 11(2):175-188

Michalkiewicz B (2004) Partial oxidation of methane to formaldehyde and methanol using molecular oxygen over Fe-ZSM-5. Appl Catal A 277(1-2):147-153

Mittal A, Teotia M, Soni RK et al (2016) Applications of egg shell and egg shell membrane as adsorbents: a review. J Mol Liq 223:376-387

Ravi M, Ranocchiari M, van Bokhoven JA (2017) The direct catalytic oxidation of methane to methanol_A critical assessment. Angew Chem Int Ed 56(52):16464-16483

Roseno KTC, Brackmann R, da Silva MA et al (2016) Investigation of LaCoO3, $\mathrm{LaFeO} 3$ and $\mathrm{LaCo} 0.5 \mathrm{Fe} 0.5 \mathrm{O} 3$ perovskites as catalyst precursors for syngas production by partial oxidation of methane. Int J Hydrogen Energ 41(40):18178-18192

Sankaran R, Show PL, Ooi C et al (2020) Feasibility assessment of removal of heavy metals and soluble microbial products from aqueous solutions using eggshell wastes. Clean Techn Environ Policy 22(4):773-786

Santos S, Nobre L, Gomes J et al (2019) Soybean oil transesterification for biodiesel production with micro-structured calcium oxide $(\mathrm{CaO})$ from natural waste materials as a heterogeneous catalyst. Energies 12(24):4670

Schwach P, Pan X, Bao X (2017) Direct conversion of methane to value-added chemicals over heterogeneous catalysts: challenges and prospects. Chem Rev 117(13):8497-8520

Shahbandeh M (2020) Global egg production from 1990 to 2018. https:// www.statista.com/statistics/263972/egg-production-worldwide-since -1990/. Accessed 13 Mar 2020

Sharma R, Poelman H, Marin GB et al (2020) Approaches for selective oxidation of methane to methanol. Catalysts 10(2):194

Simpson BK, Aryee AN, Toldrá F (2019) Byproducts from agriculture and fisheries: adding value for food feed, pharma and fuels. Wiley, Hoboken

Tan YH, Abdullah MO, Nolasco-Hipolito C et al (2017) Application of RSM and Taguchi methods for optimizing the transesterification of waste cooking oil catalyzed by solid ostrich and chicken-eggshell derived $\mathrm{CaO}$. Renew Energy 114:437-447

Tizo MS, Blanco LAV, Cagas ACQ et al (2018) Efficiency of calcium carbonate from eggshells as an adsorbent for cadmium removal in aqueous solution. Sustain Environ Res 28(6):326-332

Vereshchagin SN, Kondratenko EV, Rabchevskii EV, Anshits NN, Solov'ev LA, Anshits AG (2012) New approach to the preparation of catalysts for the oxidative coupling of methane. Kinet catal 53:449-455

Waheed M, Butt MS, Shehzad A et al (2019) Eggshell calcium: A cheap alternative to expensive supplements. Trends Food Sci Technol 91:219-230 
Wang Y, Dong Li A, Zhang QH (2010) Catalytic selective oxidation or oxidative functionalization of methane and ethane to organic oxygenates. Sci China 53(2):337-350

Xu J, Armstrong RD, Shaw G et al (2016) Continuous selective oxidation of methane to methanol over $\mathrm{Cu}$-and Fe-modified ZSM-5 catalysts in a flow reactor. Catal Today 270:93-100

York AP, Xiao T, Green ML (2003) Brief overview of the partial oxidation of methane to synthesis gas. Top Catal 22(3-4):345-358
Zhang T, Tu Z, Lu G et al (2017) Removal of heavy metals from acid mine drainage using chicken eggshells in column mode. J Environ Manage 188:1-8

\section{Publisher's Note}

Springer Nature remains neutral with regard to jurisdictional claims in published maps and institutional affiliations.

\section{Submit your manuscript to a SpringerOpen ${ }^{\circ}$ journal and benefit from:}

- Convenient online submission

- Rigorous peer review

- Open access: articles freely available online

- High visibility within the field

- Retaining the copyright to your article

Submit your next manuscript at $\mathbf{s p r i n g e r o p e n . c o m ~}$ 